\title{
Quality metrics for lung cancer care: Far from perfect, but close to reality
}

\author{
Robert J. Korst, MD, MBA, ${ }^{a, b, c}$ and Sobeida Santana-Joseph, MSN, RN, NE-BC, OCN ${ }^{b}$
}

From the ${ }^{a}$ Department of Thoracic Surgery, Mount Sinai Health System, Icahn School of Medicine at Mount Sinai, New York, NY; the ${ }^{\mathrm{b}}$ Valley/Mount Sinai Comprehensive Cancer Care, Paramus, NJ; and the ${ }^{\mathrm{c}}$ Department of Surgery, The Valley Hospital, Ridgewood, NJ.

Disclosures: Authors have nothing to disclose with regard to commercial support.

Received for publication Oct 19, 2018; accepted for publication Oct 20, 2018; available ahead of print Dec 8, 2018.

Address for reprints: Robert J. Korst, MD, MBA, Valley/Mount Sinai Comprehensive Cancer Care, 1 Valley Health Plaza, Paramus, NJ 07652 (E-mail: korsro@valleyhealth.com).

J Thorac Cardiovasc Surg 2019;157:1238

$0022-5223 / \$ 36.00$

Copyright $\subset 2018$ by The American Association for Thoracic Surgery

https://doi.org/10.1016/j.jtcvs.2018.10.084

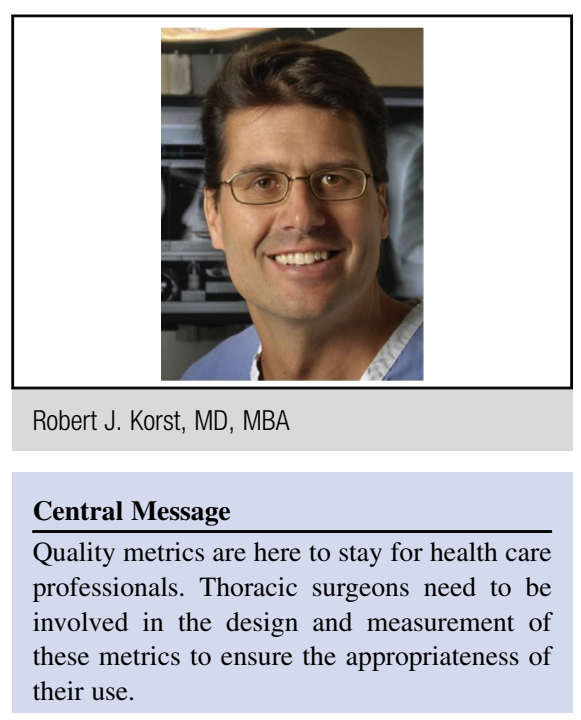

See Article page 1219 .
In health care today, as we enter the era of optimizing value, measurement of the quality of care delivered by practitioners has moved rapidly to the forefront. To this end, the American College of Surgeons' Commission on Cancer (CoC) has begun to incorporate clinical quality metrics into their accreditation process for institutions that deliver cancer care. Performance in these quality metrics is intended to provide institutions with the feedback needed to guide future quality improvement processes.

In this issue of The Journal of Thoracic and Cardiovascular Surgery, Odell and colleagues ${ }^{1}$ present a retrospective, observational study of patients with non-small cell lung cancer to determine adherence to quality metrics that were first proposed by the $\mathrm{CoC}$ in 2014. To accomplish this, they queried the National Cancer Database for data from member institutions between 1998 and 2011. Odell and colleagues ${ }^{1}$ found that adherence to the $4 \mathrm{CoC}$ proposed metrics was extremely variable according to the metric being examined. Adequate surgical lymph node staging and the referral rate for adjuvant therapy after resection were poor, and the timing of surgery after neoadjuvant therapy and the lack of the use of up-front surgery for patients with clinical N2 disease were far higher adherence to adequate surgical lymph node staging and the referral rate for adjuvant therapy. In addition, survival was significantly improved in patients in whom the metric was achieved for 3 of 4 of these measures. Given the emphasis placed on value in the healthcare environment today, Odell and colleagues ${ }^{1}$ are to be commended on addressing such a timely research topic in their study and correctly pointing out that there is room for quality improvement for patients with surgically managed non-small cell lung cancer.

Although the study clearly demonstrates the adherence rates to the CoC-proposed metrics, drawing definitive conclusions about quality and survival from the data is more

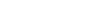

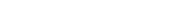

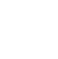

-

See Article page 1219.

challenging. First, the definition of quality for each of the metrics proposed by the $\mathrm{CoC}$ is arbitrary at best. For
example, the use of 10 resected lymph nodes as a definition of adequate staging does not take into account the location and number of nodal stations sampled and the fact that many nodes are removed in a fragmented state. In addition, lymph node count also depends as much on pathologic assessment as it does on completeness of surgical sampling. Second, measuring the adherence to guidelines during a period when the guidelines and modern standards of care did not yet exist is of limited utility going forward. Finally, conclusions regarding survival are difficult to draw from the presented analysis when a large number of variables will affect both physician conduct in any individual case as well as the survival of an individual patient.

Quality measures, both at the institutional level (as described in the article of Odell and colleagues ${ }^{1}$ ) and at the individual practitioner level, are the way of the future as society tries to optimize the value obtained from health care delivery. Not only will quality metrics affect accreditation of entities, their measurement will most certainly permeate deeply into reimbursement practices.

\section{Reference}

1. Odell DD, Feinglass J, Engelhardt K, Papastefan S, Meyerson SL, Bharat A, et al. Evaluation of adherence to the commission on cancer lung cancer quality measures. J Thorac Cardiovasc Surg. 2019;157:1219-35. 